HART, F. D., Golding, J. R. (1960): Rheumatoid Neuropathy, Brit. med. J., i, 1594.

Hingorani, K., and GrahaM, G. S. (1963): Smallbowel Necrosis due to Arteritis in Rheumatoid Disease, Ann. phys. Med., 7, 68.

Heptinstall, R. H., and Sowry, G. S. C. (1952): Peripheral Neuritis in Systemic Lupus Erythematosus, Brit. med. J., i, 525.

Kemper, J. W., Baggenstross, A. H., and Slocumb, C. H. (1957): The Relationship of Therapy with Cortisone to the Incidence of Vascular Lesions in Rheumatoid Arthritis, Ann. intern. Med., 46, 831.

KIBleR, R. F., and Rose, F. C. (1960): Peripheral Neuropathy in the Collagen Diseases. A case of Scleroderma Neuropathy, Brit. med. J., i, 1781.

LeVIN, M. H., Rivo, J. B., SCOTT, W., FigueroA, W. G., Fred, L., and BARreTt, T. F. (1953): The Prolonged Treatment of Rheumatoid Arthritis with Cortisone and Corticotrophin, Amer. J. Med., 14, 265.

McKeown, K. C., and Ganguli, A. K. (1956): Gastro-Intestinal Symptoms in Polyarteritis Nodosa, Brit. J. Surg., 44, 308.

Parker, R. A., and Thomas, P. M. (1959): Intestinal Perforation and Widespread Arteritis in Rheuma- toid Arthritis during Treatment with Cortisone, 으 Brit. med. J., i, 540.

Rabinovitch, J., and Rabinovitch, S. (1954): In- $\mathbb{\Phi}$ farction of the Small Intestine sequent to Poly- $c$ arteritis of the Mesenteric Vessels, Amer. J. Surg., 88, 896.

Ropes, M. W., Bennett, G. A., CoBb, S., Jacox, R., $\stackrel{\text { I }}{\square}$ and Jessar, R. A. (1958): Diagnostic Criteria for Rheumatoid Arthritis, Bull. rheum. Dis., 9, 175.

ROSE, G. A., and SPENCER, H. (1957): Polyarteritis $\frac{\bar{\rho}}{J}$ Nodosa, Quart. J. Med., 26, 43.

SCHMID, F. R., COOPER, N. S., ZIFF, M., and $\varrho$ MCEWEN, C. (1961): Arteritis in Rheumatoid कै Arthritis, Amer. J. Med., 30, 56.

STEINBERG, V. L. (1960): Neuropathy in Rheumatoid $\vec{\circ}$ Disease, Brit. med. J., i, 1600.

STOlzer, B. L., BarR, J. H., EISEnbeis, C. H., $\vec{\omega}$ WeChSler, R. L., and Margolis, H. M. (1957): Prednisone and Prednisolone Therapy in Rheuma-ce toid Arthritis, J. Amer. med. Ass., 165, 13.

Walton, E. W. (1958): Giant-cell Granuloma of the Respiratory Tract (Wegener's Granulomatosis), $\stackrel{ \pm}{\rightarrow}$ Brit. med. J., ii, 265.

West, H. F., and Newns, G. R. (1953): Cortisone $\longrightarrow$ and Rheumatoid Disease, Lancet, ii, 1123

\title{
EOSINOPHILIC INFILTRATION OF THE STOMACH AND DUODENUM COMPLICATED BY PERFORATION
}

\author{
J. Y. W. Russell, M.B., Ch.B., F.R.C.S.E. \\ Consultant Surgeon. \\ Preston \& Chorley Hospitals
}

\author{
G. Evangelou, M.D. \\ Resident Surgical Officer. \\ Chorley \& District Hospital
}

THE PRESENCE of diffuse thickening of the stomach and duodenum and also of the upper part of the small intestine due to eosinophilic infiltration has been observed during recent years by several authors and the condition is now very well documented. Bockus (1963) has reviewed the condition extensively. The following case is reported as it may be unique in that the infiltration was associated with perforation.

\section{Case Report}

The patient, Mr. R.H., aged 45 , a bus inspector, was admitted to hospital as an emergency on 5.3.63 with severe abdominal pain and vomiting. His pain had begun suddenly at 4 a.m. It was located initially in the right iliac fossa but it had soon spread to become generalised over the whole obdomen. Vomiting had occurred soon after the onset of the pain and had recurred twice, the vomitus being watery and copious. He had had a normal bowel action on the day prior to admission.

He gave a history of chronic bronchitis of many years duration. In association with this, hæmoptysis had occurred on two occasions. Some twelve years previously, he had developed a contact dermatitis with motor oil and he was obliged to change his job. More recently he had had some upper abdominal discomfort. He reported this to his family doctor on the day prior to admission and he was found to have some upper abdominal tenderness. Gall bladder pathology was suspeoted.

On examination he was obviously in great pain; pulse 92 , temperature $96^{\circ} \mathrm{F}$. His tongue was moist and clean. The abdomen was held rigidly with very little movement on respiration and was diffusely guarded and tender with marked rebound tenderness. The liver dullness was not diminished. Rectal cxamination was negative. A few adventitious sounds were heard in the chest but air entry was reasonably good.

Investigations: Hb. $120 \%$, PCV $61 \%$, MCHC $29 \%$, WBC $20,000 / \mathrm{cu}$. mm. with a polymorphonuclear leucocytosis. An X-ray of the chest showed some linear shadowing at both bases suggesting possible lower lobe shrinkage or minimal inflammatory change. A plain film of the abdomen revealed the presence of a pneumoperitoneum with apparently normal bowel shadows. An emergency operation was decided upon with a provisional diagnosis of perforation of a peptic ulcer.

Operation (5.3.63). Exploration under general anæsthesia was carried out through an upper right paramedian incision. On opening the peritoneum a considerable quantity of free turbid fluid was encountered and this was aspirated. A large per- 


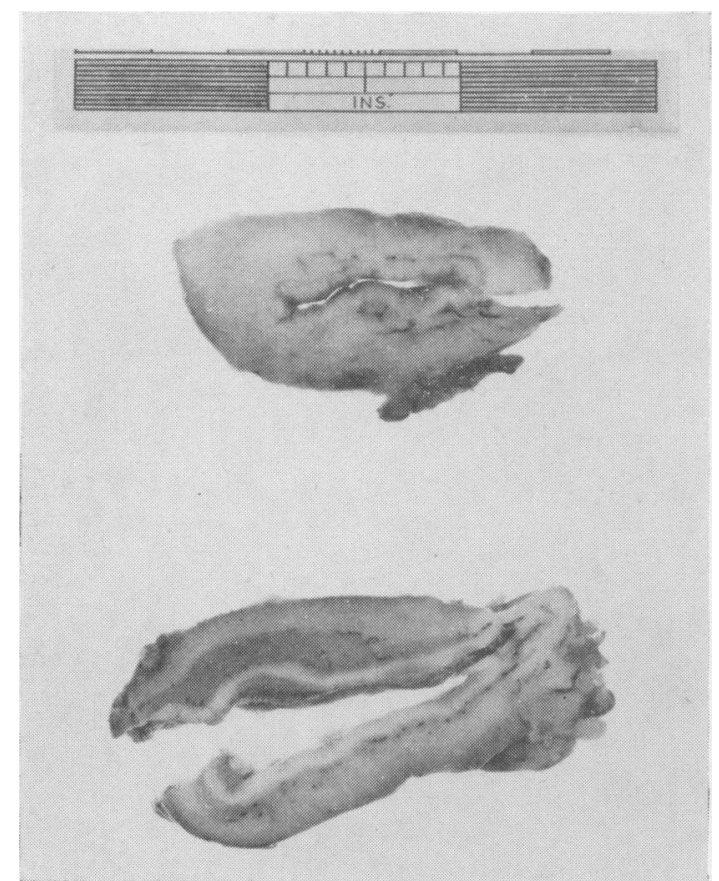

FIG. 1.-Low power view of sections of pyloric antrum.

foration of a huge peptic ulcer was located in the first part of the duodenum. The perforation measured some $3 \mathrm{~cm}$. in diameter and extended practically from one edge of the duodenum to the other. There was very marked thickening, induration and œdema. Because of the size of the perforation and associated great thickening of the gastroduodenal segment it was decided that an immediate partial resection of the stomach would be the best line of treatment to adopt and this was carried out. At the proximal level of section of the stomach the wall was fairly normal and presented no difficulties in handling and suturing, an ante-colic valvular gastro-jejunal anastomosis being made. Distally, closure of the duodenal stump proved to be extremely difficult because of the marked induration present. It was however, ultimately achieved and an omental patch was applied. A large drainage tube was passed down to the duodenal stump through a separate stab incision on closure of the abdomen.

Post-operative treatment was by intravenous drip transfusion, continuous gastric suction, antibiotics and physiotherapy, the latter being particularly directed at his respiratory condition. His general condition rapidly improved but on the second postoperative day slight discharge of bile took place from the drainage tube and a fistula was soon established. This was treated by continuous suction and gave rise to no great anxiety as normal peristaltic activity re-appeared and within a few days the patient was taking a light diet without apparent difficulty and bowel action was resumed. Drainage from the fistula gradually diminished and it appeared that he was going to make a good recovery. On 20.3.63, however, slight vomiting took place and this was repeated on a few occasions on each of the following

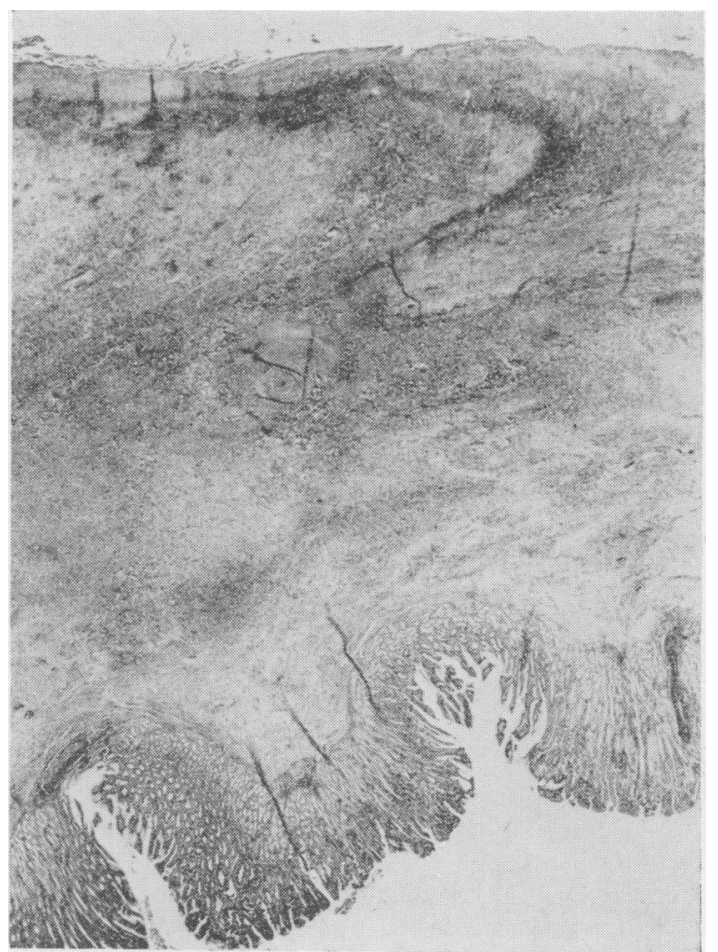

FIG. 2.-Lower power view $(X 8)$ showing infiltratration and great thickening of gastric wall.

days, small amounts of brownish fluid being voided. By this time drainage from the fistula had practically ceased and the tube was removed on 25.3.63. He began to develop a rather troublesome cough with production of a good deal of muco-purulent sputum and some frank blood was present on 26.3.63. Later in the same day he suddenly collapsed and died.

Pathology. Gastrectomy specimen (Fig. 1). The specimen comprised the distal part of the stomach with the pylorus and about $2 \mathrm{~cm}$. of the duodenal bulb. On the lesser curvature of the stomach, about $6 \mathrm{~cm}$. from the pylorus, there was a small $(1 \mathrm{~cm}$.) chronic ulcer which appeared benign. Parallel sections of the pyloric, prepyloric and antral walls showed marked thickening $(2 \mathrm{~cm}$.) of submucosa and muscularis. The edge of a chronic peptic ulcer was present on the anterior surface of the duodenum at the level of section. Microscopy of the pylorus and prepyloric area showed dense infiltration with inflammatory cells including numerous œsinophils. In the submucosa and muscularis the exudate almost entirely consisted of œsinophils. (Fig. 2-4). Both the gastric and duodenal ulcers were benign in appearance.

Necropsy: 48 hours after death. The cause of death was suppurative broncho-pneumonia and acute peritonitis. There was acute diffuse peritonitis due to escape of bile and bowel contents from the proximal end of the duodenum. There was a small amount of pus on the peritoneal surface. The anastomosis between residual stomach and the jejunum was intact; the cardiac part of the stomach appeared normal; the lower end of the csophagus showed chronic inflammatory changes. Other abdominal organs appeared normal excepting the 


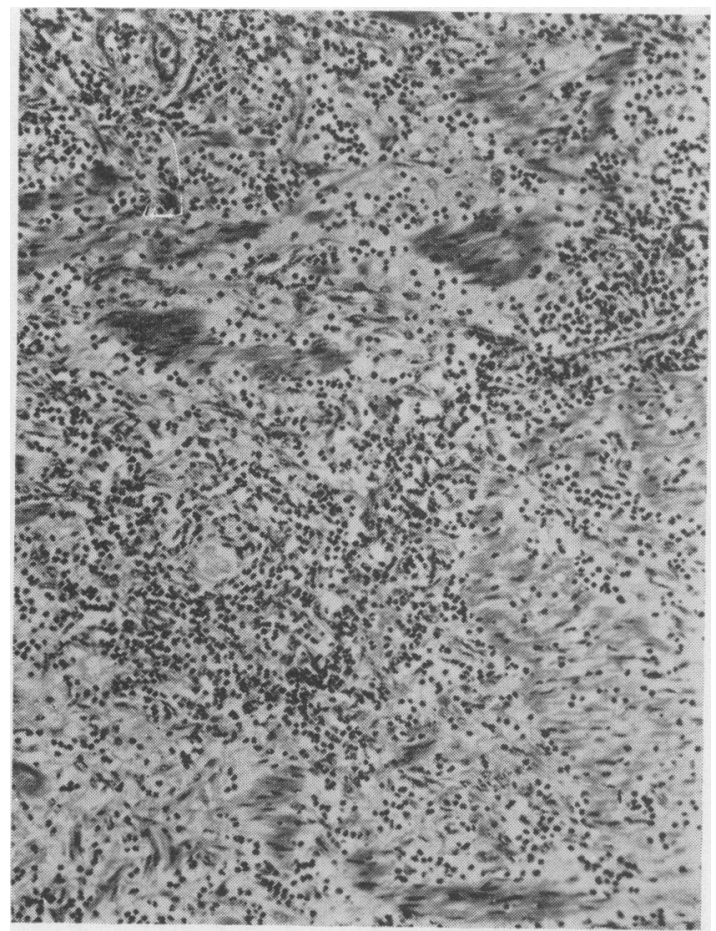

FIG. 3.-(H.E. $x$ 100) showing intense infiltration of eosinophils.

peritonitis. Both lungs showed bronchiectasis and suppurative bronchopneumonia. The heart was enlarged due to hypertensive hypertrophy of the left ventricular wall and interventricular septum: there was mitral stenosis.

Histology. The duodenum showed marked inflammatory changes. Sections of the duodenum showed few eosinophils in comparison with the marked eosinophilia of the pylorus.

The gall bladder, cardiac end of stomach, oesophagus, heart, lungs and kidneys were examined but did not show evidence of eosinophilia.

Bacteriology: Pus from the peritoneal cavity gave a profuse mixed growth of $B$. proteus and nonhæmolytic streptococci together with a scanty growth of Staphylococcus aureus.

\section{Discussion}

According to Permyokova and Loginon (1961) who have reviewed the literature very fully, some 60 cases of eosinophilic granuloma localised in the stomach have been reported. Blackwell and Gild (1952) described 12 cases of diffuse eosinophilic infiltration involving the gastro-duodenal segment including one case of their own and 21 cases of eosinophilic granuloma and pointed out the difference between these two types. In addition they described 5 further cases of intermediate form.

It would appear that this is the first recorded case of eosinophilic infiltration of the gastroduodenal segment complicated by perforation. It is interesting that the large anterior duodenal

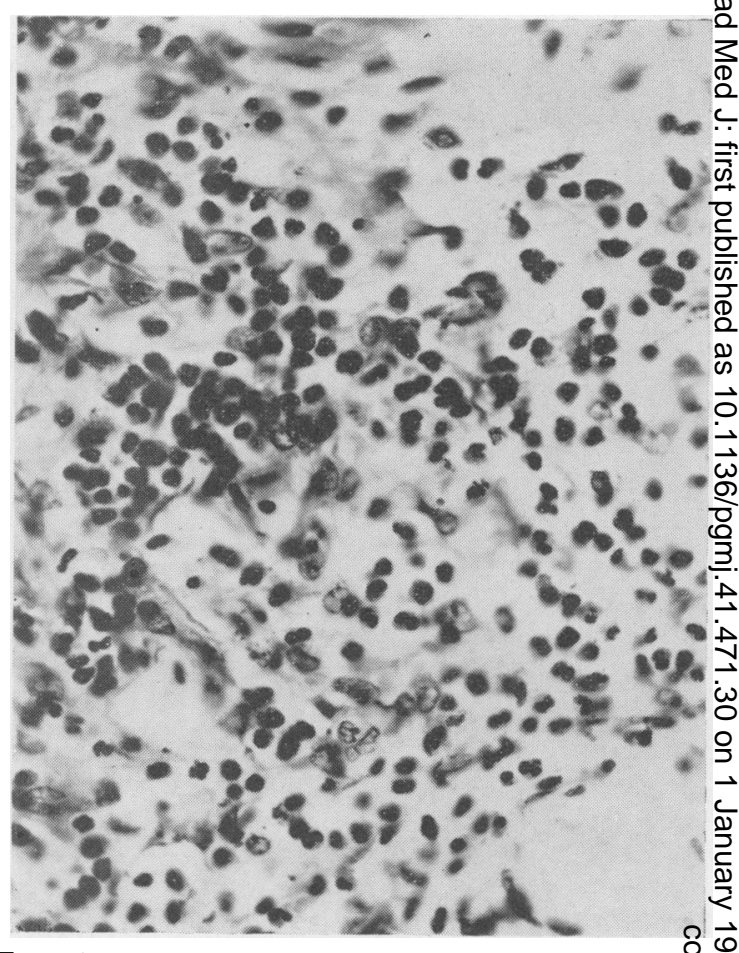

FIG. 4.-(H.P. X 400) Eosinophils clearly demo strated.

ulcer was associated with a small benign chronte ulcer on the lesser curvature of the stomach. A similar ulcer was present in the case described by Blackwell and Gild. It is possible that the gastric ulcer arose as a result of some degree of pyloric $\stackrel{\mathbb{D}}{\circ}$ hold-up.

In cases previously recorded eosinophilia has been a feature. In this case careful search in this connection was not made until after receipt of the histological findings in the resected specimen. Eosinophilia was not present but it may possibly 흥 have been present prior to the operation when the 3 total white cell count was $20,000 / \mathrm{cu}$. mm. It is noteworthy that in Orr, Miller and Russell's case (1954) the eosinophil count in the blood was still 8 very much raised at $1,170 / \mathrm{cu}$. mm. one month after gastroduodenal resection.

In the post-operative period the application of allergens to the skin produced numerous positive $\frac{T}{0}$ reactions. Tests with 'horse dust', straw, flowers and various moulds were all positive although $N$ in varying degree. It is interesting that he gave a previous history of allergic contact dermatitis $N$ from motor oil.

With regard to treatment, it has been generally $O$ recommended that this should, as a rule, be conservative. There will, however, be many cases in

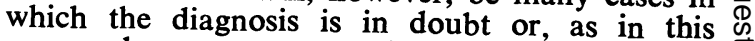
case, where some complication of associated pathology may be present making laparotomy essential with necessity to proceed to resection of the involved area. 
The fatal outcome in the case described was unfortunate but was undoubtedly largely attributable to the patient's respiratory condition. The great difficulty which may be encountered in closing the duodenal stump in the presence of massive infiltration must, however, be stressed.

We are indebted to Dr. A. A. Miller for valuable assistance with the pathological studies and for helpful advice.

\section{REFERENCES}

Blackwell, J. B., and GiLD, A. (1962): Eosinophilic Infiltration of the Stomach. Review of the literature and case report, Aust. N.Z.J. Surg., 32, 66.

BockUS, H. L. (1963): Gastro-enterology, Vol. 1, p. 864-869. London: W. B. Saunders.

OrR, I. M., Miller, A. A., and Russell, J. Y. W. (1954): Eosinophilic Infiltration of the Stomach and Bowel, Postgrad. med. J., 30, 485.

Permyokova and Loginon, E. N. (1961): Eosinophilic Granuloma of the Stomach, Vop. Onkol., 7, 74.

\section{LONG-TERM REMISSION FOLLOWING}

\section{METHOTREXATE THERAPY IN A CASE OF HAND-SCHULLER-CHRISTIAN DISEASE}

\author{
K. A. Newton, M.R.C.P., F.F.R. \\ Consultant Radiotherapist
}

I. M. ANDERSON, M.D., F.R.C.P. Physician, Childrens' Department

Westminster Hospital, London, S.W.1.

THE CONDITION now known as Hand-SchüllerChristian disease, derived its title following the descriptions of Hand in 1893, Schüller in 1915 and Christian in 1919, of a symptom complex characterised by defects in membranous bones, exophthalmos and diabetes insipidus. This triad was specifically referred to by Christian in 1919 . (Moe and Hansen, 1960).

Letterer-Siwe disease, Hand-Schüller-Christian disease and eosinophilic granuloma are related clinically, pathologically and probably ætiologically (Lahey, 1962). They are usually classified together under the heading of the nonlipid reticuloendothelioses (as distinct from the lipid reticuloendothelioses, Gaucher's and NiemannPick disease). (Luhby, 1960).

Opinions vary concerning the aetiology of this group of disorders and indeed some doubt exists as to whether they can be truly classified amongst the malignancies of childhood. If it is accepted that all three conditions (Hand-Schüller-Christian disease, Letterer-Siwe disease and eosinophilic granuloma) are varieties of the same essential disorder, then it is convenient to regard LettererSiwe as the most malignant and rapidly progressive, eosinophilic granuloma the most benign and easiest to control, while Hand-SchullerChristian can be considered in an intermediate group. The prognosis of eosinophilic granuloma, which tends to occur in older children, is often excellent whether treated by surgery or radio- therapy, whilst the prognosis of Letterer-Siwe disease, of rapid onset, is almost invariably poor. In Hand-Schüller-Christian disease the prognosis is extremely variable and survival to adult years has been recorded.

The accepted treatment for Hand-SchüllerChristian disease is radiotherapy to control symptoms due to local tumour formation, chemotherapy in the form of alkylating agents in an attempt to reduce the degree of visceral involvement, and steroids which may on occasion, by their sole use, bring about dramatic remission. (Mermann and Dargeon, 1955).

A case is described of histologically and clinically accepted Hand-Schuller-Christian disease, that prior to his admission to Westminster Hospital had been treated by radiotherapy and alkylating agents and steroids without control, but which underwent dramatic regression of advanced disease immediately following the administration of the antifolic substance, methotrexate (4-amino- $\mathrm{N}^{10}$-methyl-pteroyl-glutamic acid).

Case Report. This boy (D.C.), aged 10, born 9.5.50 weighing 6 lbs. 8 ozs., only child of healthy parents, was admitted to hospital in December 1959 having previously suffered only from the usual childhood ailments. At the time of admission to hospital, he was complaining of malaise, headaches and backache of only one week's duration. A lump was observed which appeared to be arising from the left frontal bone. Biopsy which was taken from this site 